\title{
Failure Mode Analysis of Carbon Fiber Composite Laminates by Acoustic Emission Signals
}

\author{
Xinye Liu, ${ }^{1}$ Xinyue Yao, ${ }^{2}$ Jinhui Cai ${ }^{D},{ }^{1}$ Jiusun Zeng, ${ }^{1}$ and Wingkong Chiu ${ }^{2}$ \\ ${ }^{1}$ College of Metrology and Measurement Engineering, China Jiliang University, Hangzhou 310018, China \\ ${ }^{2}$ Department of Mechanical and Aerospace Engineering, Monash University, Melbourne 3800, Australia \\ Correspondence should be addressed to Jinhui Cai; caijinhui@cjlu.edu.cn
}

Received 10 November 2020; Accepted 19 December 2020; Published 5 January 2021

Academic Editor: Jinyang Xu

Copyright (c) 2021 Xinye Liu et al. This is an open access article distributed under the Creative Commons Attribution License, which permits unrestricted use, distribution, and reproduction in any medium, provided the original work is properly cited.

Composite laminates have complex failure modes. In order to investigate the evolution of failure in the composite laminates, this paper performed an experimental study on four laminates with different layups using acoustic emission (AE) technique. Two different kinds of defects are imposed on the laminates, including a hole and a crack in the center. Tensile and bending tests are performed on the defective laminates and real-time AE signals are collected. By analyzing the spectrograms of the obtained $\mathrm{AE}$ signals and integrating with the dispersion curves, the evolution of failure modes for different laminates can be observed. The tests show that the defects cause multiple failure modes, which change gradually during the experiments. It is also revealed that laminates with different layups have different failure modes. More specifically, the stacking order of different plies has a greater impact on the occurrence of delamination and fiber fracture than matrix crack. The tentative research shows that there is great potential for improving the performance of the composite laminates by careful selection of ply layups.

\section{Introduction}

Carbon fiber reinforced polymer composite (CFRP) material uses thermoplastic polymer resin as its matrices and carbon fiber as the reinforcing fibers. By assembling and joining layers of CFRP materials, the composite laminates have good engineering properties, including high strength, good bending/in-plane stiffness, and great coefficient of thermal expansion, among others. As a result, the composite laminates have seen wide applications in fields like aircraft structures, military products, and automotive components [1-3]. During the lifespan of the composite laminates, different kinds of failure may happen, including matrix crack, delamination, and fiber fracture. Failure of the composite laminates will cause a decrease in the strength and stiffness, which may eventually cause failure of equipment made from them. In order to improve the safety and reliability of such equipment, it becomes very important to investigate the failure mechanism of the composite laminates. This realistic need has attracted the attention of many researchers. For example, Smith and Pascoe [4] found that the strength and failure modes of laminates in different stacking sequences are different. Liu and Zheng [5] used continuum damage mechanics to analyze the progressive failure of composite laminates. Kondo et al. [6] performed fracture resistance analysis on carbon/epoxy composite laminates under different failure modes. Liu et al. [7] used finite element analysis to investigate the dynamic progressive failure of carbon fiber composite laminates.

Another important research direction on failure mechanism analysis of the composite laminates is the use of nondestructive techniques like acoustic emission (AE), which has become one of the most widely used techniques in structure health monitoring (SHM) [8-11]. AE is a phenomenon that releases strain energy in the form of transient elastic wave when a material undergoes damage. Hence, detecting and analyzing the AE signals originated from a damaged structure is helpful for obtaining valuable knowledge about the damage. The detection of AE signals is generally based on the Lamb wave. Once the AE signals under different failure modes are obtained, frequency analysis will be used to characterize the failure. The 
application of $\mathrm{AE}$ on failure analysis of composite laminates leads to a series of research outputs, which mainly focused on 3 types of failure, namely, matrix crack, delamination, and fiber fracture. Baker et al. [12] studied the influence of $90^{\circ}$ ply position and thickness on the development of transverse cracks in laminates based on the principle of modal acoustic emission, coupling the peak frequency data with acoustic energy of waveforms. Yousefi and Mohamadi [13] established a connection between the initiation and propagation of delamination and the obtained $\mathrm{AE}$ features and combined the cohesive zone model (CZM) and scanning electron microscope (SEM) images to analyze the delamination through microscopic and macroscopic methods. Woo and Choi [14] analyzed the fracture process of singleedge-notched laminated composites with different layup configurations and different fiber composite systems based on the behavior of high-amplitude acoustic emission signals and the classification of signal type according to the dominant frequency band and its magnitude via FFT. Michalcova et al. [15] used the acoustic emission method in the structural health monitoring of an integrally stiffened composite panel, and different failure mechanisms were directly linked to different sources of AE using cluster analysis. In addition, $[16,17]$ analyzed the acoustic emission signal to locate the damage as well as the mechanical properties of fiber composite materials. References [18-21] used several pattern recognition algorithms to analyze the collected $\mathrm{AE}$ signals, such as principal component analysis, $K$-means genetic algorithm, and fuzzy C-means. All these references show that $\mathrm{AE}$ technology is suitable for real-time dynamic monitoring and detection of CFRP.

It is found that each failure mode has a corresponding frequency response range. For the frequency range of matrix crack, delamination, and fiber fracture, the frequency ranges are validated from a number of our tests, which is in accordance with the experiments performed in [22-26]. For example, Sause et al. [16] confirmed these frequency ranges through numerical study, which found that the frequency ranges for matrix crack, delamination, and fiber fracture are $100-300 \mathrm{kHz}, 300-400 \mathrm{kHz}$, and $400-700 \mathrm{kHz}$. Gutkin et al. [18] used competitive neural networks to analyze the CFRP and found that the frequency ranges for matrix crack, delamination, and fiber fracture are $0-150 \mathrm{kHz}, 300-400 \mathrm{kHz}$, and $400-700 \mathrm{kHz}$. Huang et al. [23] used AE signal to analyze pure resin matrix with matrix crack, resin matrix within a carbon fiber tow and precuts delamination specimen and found that the frequency ranges are within $58-185 \mathrm{kHz}, 190-290 \mathrm{kHz}$, and $405-455 \mathrm{kHz}$. In summary, all of the above experiments show that the frequency ranges of matrix crack, delamination, and fiber fracture are within $100-300 \mathrm{kHz}, 400-550 \mathrm{kHz}$, and $600-750 \mathrm{kHz}$. Based on the above frequency ranges, failure mode identification can be performed. Despite the research progress, to the best of our knowledge, there is no work that discusses the interaction between different failure modes. Most references discuss the failure modes independently; for example, $[22,23]$ investigated the frequency ranges of different failure modes without considering their interaction and evolution. One research gap here is whether or how different failure modes interact with each other. If the interaction between different failure modes can be revealed, it will be of great help for the designing of composite laminates with better reliability and lifespan.

Based on the above analysis, this paper performs experimental study to investigate the interaction between different failure modes of the composite laminates. Four quasi-isotropic carbon/epoxy laminated composites are fabricated and damaged by introducing circular holes and cracks. The flawed laminated composites then undergo tensile and bending experiments. During the experiments, AE signals are collected and analyzed. Different from previous work on failure mode analysis that either relies on dispersion curve $[26,27]$ or spectrogram analysis $[19,24,28]$, this work conducts analysis by integrating the dispersion curve and the spectrogram analysis. By observing the obtained dispersion curve and spectrogram from the $\mathrm{AE}$ signals, the evolution and interaction of failure modes under different directional forces can be better identified. The introduction of the new failure mode analysis method consists of the main contribution of this work, which clearly reflects the relationship between plate waves and failure modes as well as the relationship between different failure modes.

\section{Experiments}

2.1. Materials. The composite laminates considered in this paper are made from carbon/epoxy prepreg. The mechanical properties of each lamina are shown in Table 1. A total of 20 laminates with randomly selected combinations of plies are considered. Tests on all the laminates show that there is obvious interaction between different failure modes. For the sake of simplicity, only four kinds of layups are presented in this paper, namely, $\left[0 / 90 / 0 / 90 / 0_{4}\right]_{s},\left[90 / 0 / 90 / 0 / 90_{4}\right]_{s},\left[0_{8}\right]_{s}$, and $\left[0 / 45 / 0 /-45 / 0_{4}\right]_{s}$. The four combinations of plies are similar to those used in [22], with a slight modification. Note that 0 corresponds to the loading direction, 45 corresponds to an angle of $45^{\circ}$ with the loading direction, and 90 corresponds to the perpendicular direction. The numeric subscripts indicate the number of layers stacked in each direction and the subscript $[\ldots]_{s}$ indicates that plies are symmetric about the midplane of the laminate. All panels have 16 plies, but the relative volume fraction of $0^{\circ}, 45^{\circ}$, and $90^{\circ}$ plies varies in each panel, as shown in Figure 1. Panels 1 and 2 contain $0^{\circ}$ and $90^{\circ}$ plies, but the number of the plies and their relative positions are different. Panel 3 contains only $0^{\circ}$ plies and panel 4 contain both $0^{\circ}$ and $45^{\circ}$ plies.

The material considered in this work is carbon/epoxy laminated composites which are manufactured using compression molding process. Plies are arranged on the aluminum plate according to the predesigned layup sequence and then pressed by a roller. After that, we cover everything with a release film to prevent the laminate from sticking to the bleeder fabric. The air is drawn out of the bag to create a vacuum. The curing process was set as $120^{\circ} \mathrm{C} /$ $100 \mathrm{kPa} / 1 \mathrm{~h}$.

Two kinds of defects are imposed on the composite laminates, as shown in Figure 2. The purpose of introducing 
TABLE 1: The mechanical properties of each lamina.

\begin{tabular}{lccccc}
\hline$\rho / \mathrm{g} \mathrm{cm}^{-3}$ & $E_{11}(\mathrm{GPa})$ & $E_{33}(\mathrm{GPa})$ & $G_{13}(\mathrm{GPa})$ & $v_{12}$ & \\
\hline 1.605 & 8.7 & 126.6 & 3.7 & 0.49 & 0.022 \\
\hline
\end{tabular}

\begin{tabular}{|c|c|c|c|}
\hline $\begin{array}{c}\text { Panel } 1 \\
\text { (16 plies) }\end{array}$ & $\begin{array}{c}\text { Panel } 2 \\
\text { (16 plies) }\end{array}$ & $\begin{array}{c}\text { Panel } 3 \\
\text { (16 plies) }\end{array}$ & $\begin{array}{c}\text { Panel } 4 \\
\text { (16 plies) }\end{array}$ \\
\hline 0 & 90 & 0 & 0 \\
\hline 90 & 0 & 0 & 45 \\
\hline 0 & 90 & 0 & 0 \\
\hline 90 & 0 & 0 & -45 \\
\hline 0 & 90 & 0 & 0 \\
\hline 0 & 90 & 0 & 0 \\
\hline 0 & 90 & 0 & 0 \\
\hline 0 & 90 & 0 & 0 \\
\hline 0 & 90 & 0 & 0 \\
\hline 0 & 90 & 0 & 0 \\
\hline 0 & 90 & 0 & 0 \\
\hline 0 & 90 & 0 & 0 \\
\hline 90 & 0 & 0 & -45 \\
\hline 0 & 90 & 0 & 0 \\
\hline 90 & 0 & 0 & 45 \\
\hline 0 & 90 & 0 & 0 \\
\hline
\end{tabular}

— Indicates midplane of composite

Figure 1: Layout details of the four composite laminates.

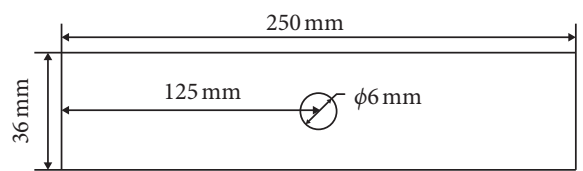

(a)

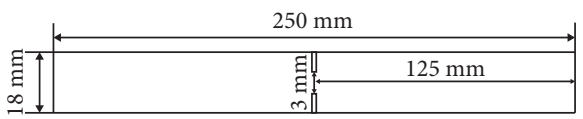

(c)

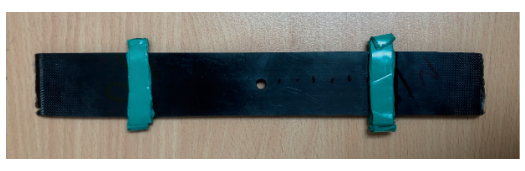

(b)

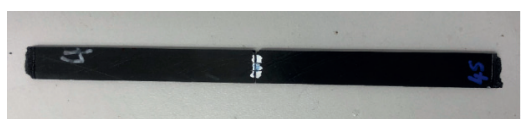

(d)

Figure 2: Test specimens. (a) Position of the hole in the specimen for tensile test. (b) Picture of specimen for tensile test. (c) Position of the cracks in the specimen for bending test. (d) Picture of specimen for bending test.

holes and cracks is to investigate the relationship between the position of early failure and the final fracture. The cracks in the three-point bending test were cut using a cutting machine, and the cracks in the tensile test were induced using a moving drill in the manufacturing factory. Figure 2(a) shows the position of the specimen where a circular hole is drilled, designed according to ASTM D57662002 [22]. This specimen will be used for tensile test. The size of the specimen is $250 \mathrm{~mm} * 36 \mathrm{~mm} * 4 \mathrm{~mm}$, and the stacking sequence of the specimens is $\left[0 / 90 / 0 / 90 / 0_{4}\right]_{s}$ and $[90 / 0 / 90 / 0 /$ $\left.90_{4}\right]_{s}$. The picture of the real specimen is shown in Figure 2(b).

On the other hand, Figure 2(c) shows the position of the cracks in the specimen used for bending test, with the picture of the real specimen shown in Figure 2(d). The size of the specimen is $250 \mathrm{~mm} * 18 \mathrm{~mm} * 4 \mathrm{~mm}$, and the stacking sequence of the specimens is $\left[0_{8}\right]_{s}$ and $\left[0 / 45 / 0 /-45 / 0_{4}\right]_{s}$.
2.2. Equipment. In the experiments, an acoustic emission system consisting of two acoustic emission sensors, a MicroSHM system with supporting software is used. The system was developed by Physical Acoustics Co., Ltd. The specification of the AE sensor is PK3I, and the sampling rate of the AE system is set as $10 \mathrm{MHz}$, with a preamplifier gain of $40 \mathrm{~dB}$ and the threshold of $38 \mathrm{~dB}$ to ensure all sensor output data are being recorded. In addition, some AE signal characteristic parameters can be applied to analysis, such as hit number, counting, and amplitude.

The tensile tests are performed on an Instron 1342 test bed. A schematic graph of the tensile testing equipment is shown in Figure 3(a). The experimental equipment requires that both ends of the specimen be clamped by $50 \mathrm{~mm}$ to prevent it from falling. In order to reduce the impact of mechanical vibration on the acoustic signal, a layer of highdamping rubber is pasted close to the fixture. The 


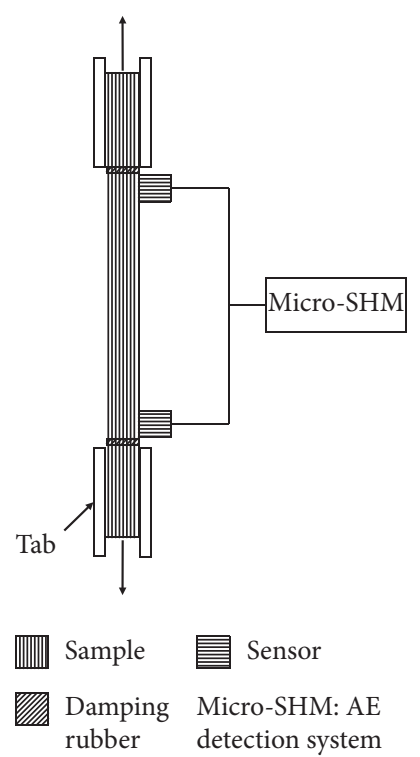

(a)

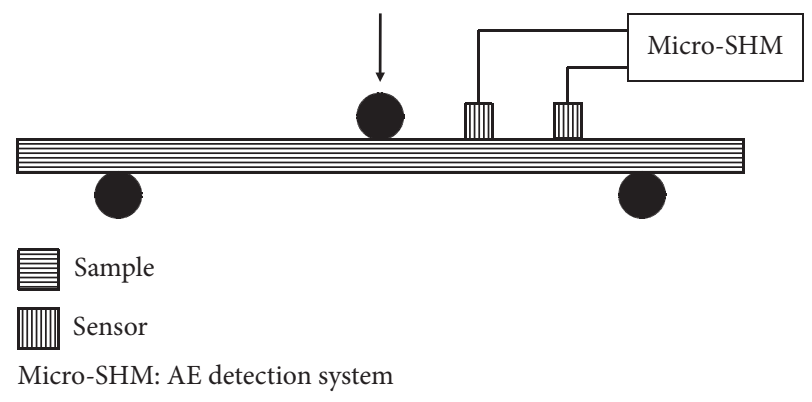

(c)

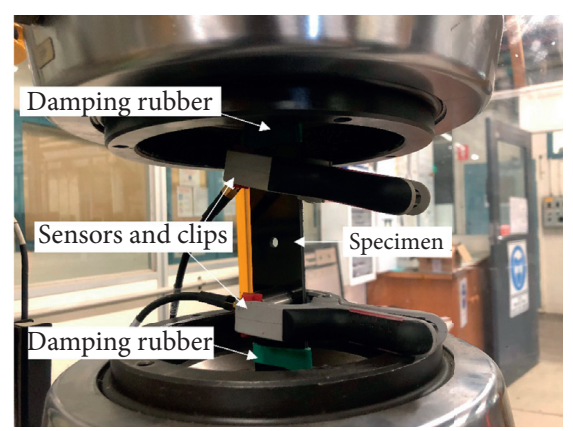

(b)

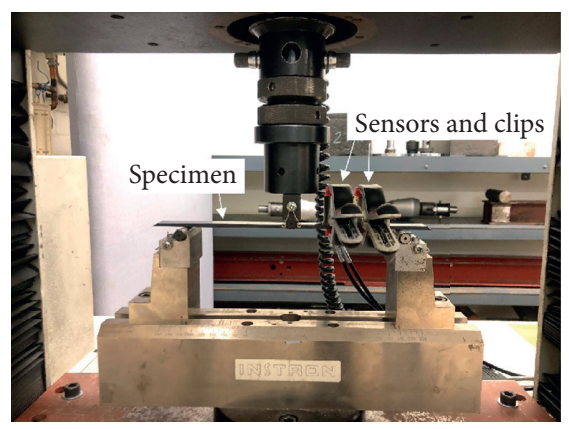

(d)

Figure 3: Experiment equipment. (a) Schematic graph of the tensile test setup. (b) Picture of the tensile test setup. (c) Schematic graph of the bending test setup. (d) Picture of the bending test setup.

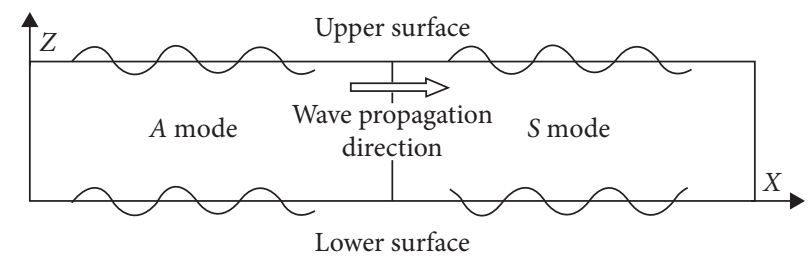

FIgURE 4: The characteristics of particle motions and deformations for $S$ and $A$ modes.

viscoelasticity of the rubber helps dampen the structural vibration and noise. Before installing the acoustic emission system, a layer of high-vacuum grease needs to be evenly coated on the sensors to reduce friction between the sensor probe and the specimen as well as prevent the sensor probe from falling. During the experiment, the two sensors are attached symmetrically around the hole of the specimen, with a distance of $40 \mathrm{~mm}$ between the hole and each sensor probe. The loading rate is set as $1 \mathrm{~mm} / \mathrm{min}$ to ensure the cracks grow slowly and steadily. The picture of sensor placement for the tensile tests is shown in Figure 3(b).
On the other hand, three-point bending tests are performed on an Instron 33R4204 test bed with a maximum force of $50 \mathrm{kN}$. The applied velocity of the bending load was $5 \mathrm{~mm} / \mathrm{min}$. The sensors were fixed on the same side, with a distance of $30 \mathrm{~mm}$. Different stacking sequence laminate types were tested, and the time curve of loading force and displacement were obtained for each test specimen [29]. The dimensions and all the procedures of the three-point bending test were in accordance with the standard ASTM D7264/D7263M-07 [30]. The schematic graph of the bending testing setup is shown in Figure 3(c). 


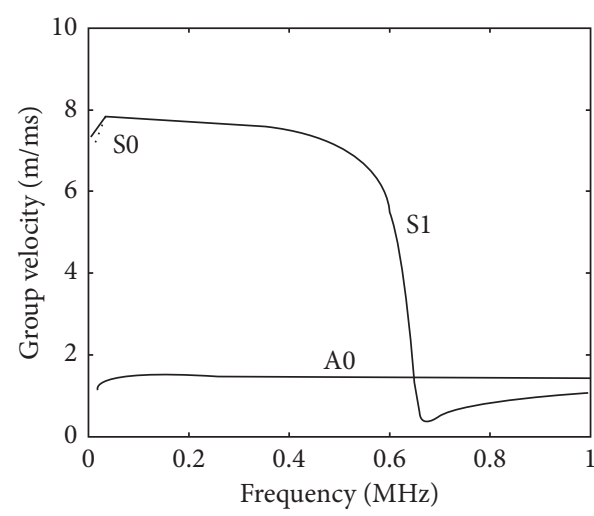

(a)

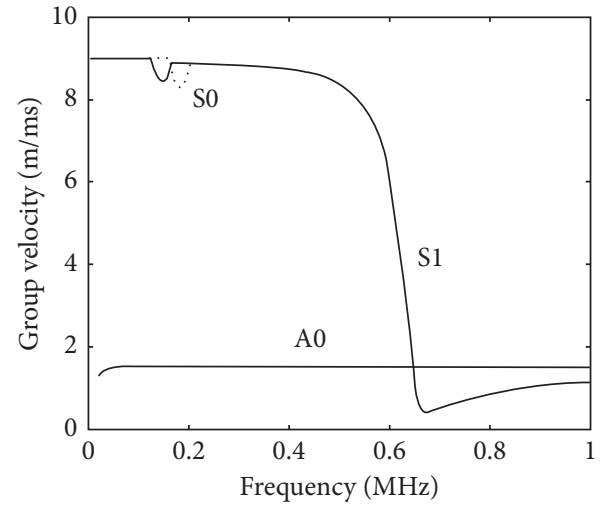

(c)

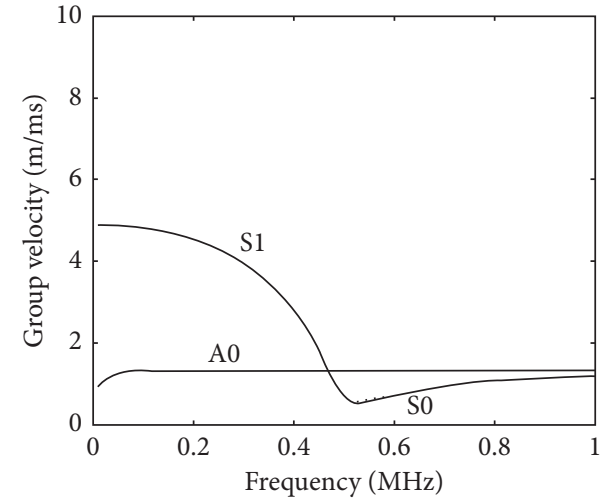

(b)

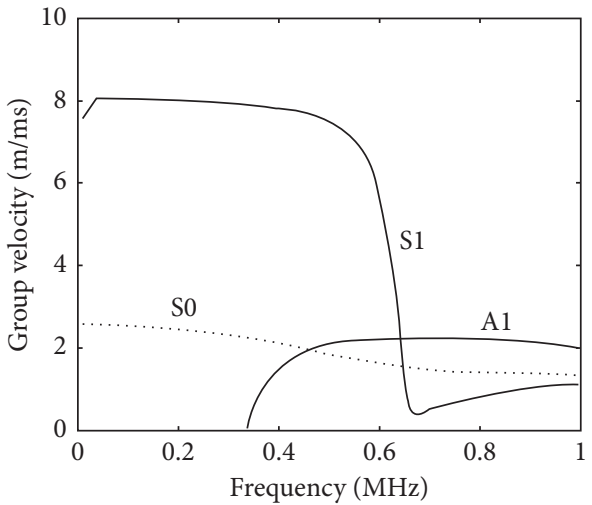

(d)

Figure 5: Dispersion curves of guided waves. (a) $\left[0 / 90 / 0 / 90 / 0_{4}\right]_{s}$. (b) $\left[90 / 0 / 90 / 0 / 90_{4}\right]_{s}$. (c) $\left[0_{8}\right]_{s}$. (d) $\left[0 / 45 / 0 /-45 / 0_{4}\right]_{s}$.

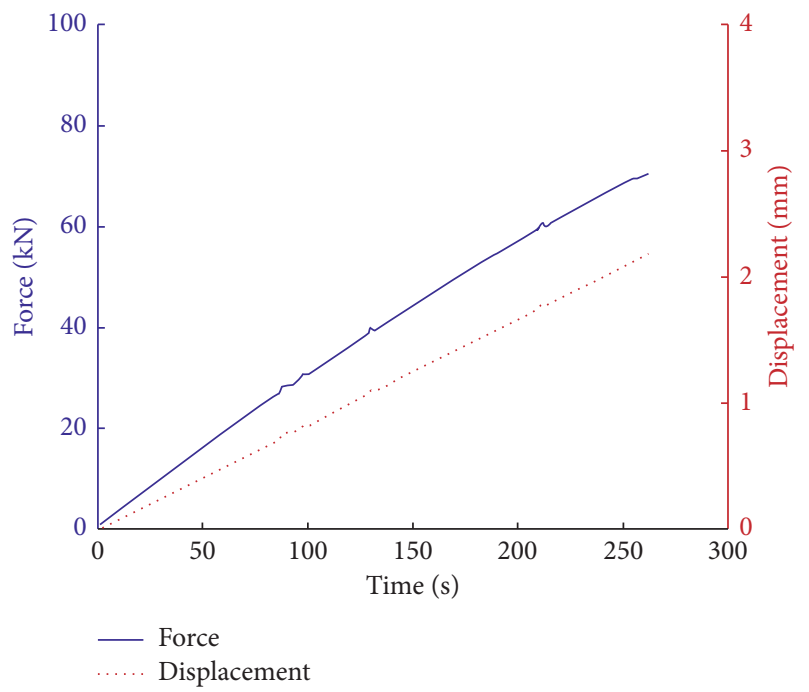

(a)

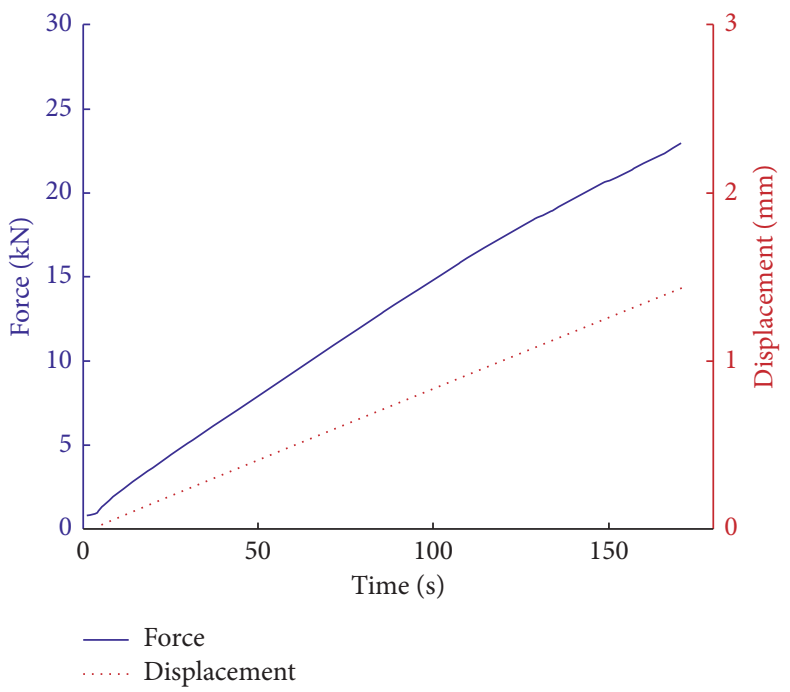

(b)

FIgURE 6: The time curves of maximum loading force and displacement. (a) $\left[0 / 90 / 0 / 90 / 0_{4}\right]_{s}$. (b) $\left[90 / 0 / 90 / 0 / 90_{4}\right]_{s}$.

The graph of sensor placement for the bending tests is shown in Figure 3(d).

2.3. Dispersion Curves. Before performing experiments, it is important to get the dispersion curve of the four composite laminates considered in this paper. Using the DISPERSE software and inputting the mechanical parameters of each laminate, the dispersion curve can be obtained. In order to simplify subsequent analysis, we use low excitation frequencies and set the cutoff frequency to $1 \mathrm{MHz}$. Four fundamental modes can be obtained: extensional modes $\left(S_{0}\right.$ 


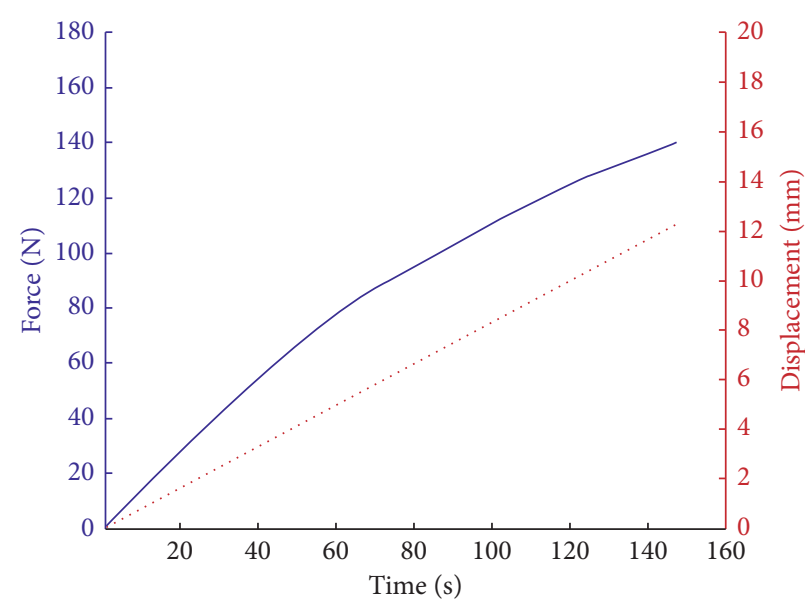

- Force

Displacement

(a)

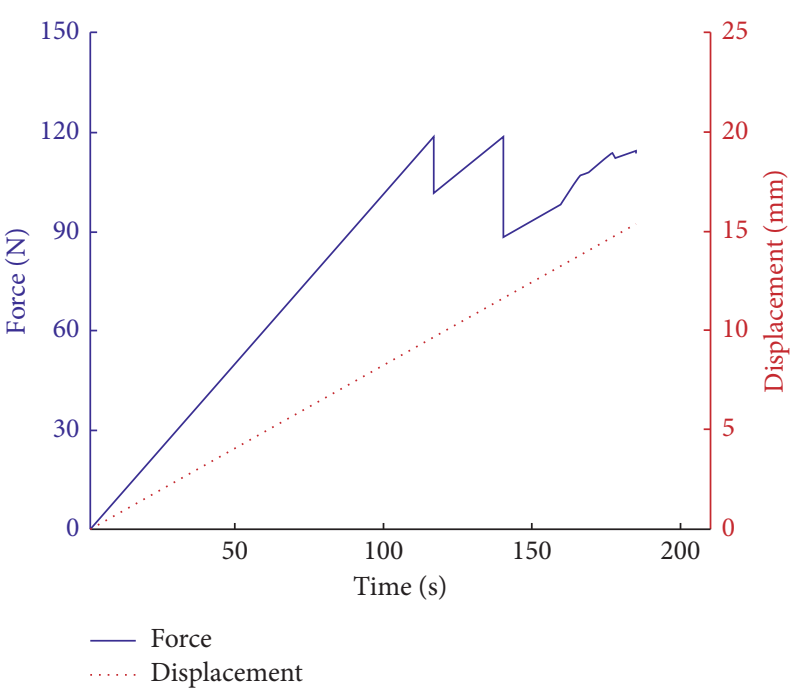

(b)

FIgURE 7: The time curve of maximum loading force and displacement. (a) $\left[0_{8}\right]_{s}$. (b) $\left[0 / 45 / 0 /-45 / 0_{4}\right]_{s}$.
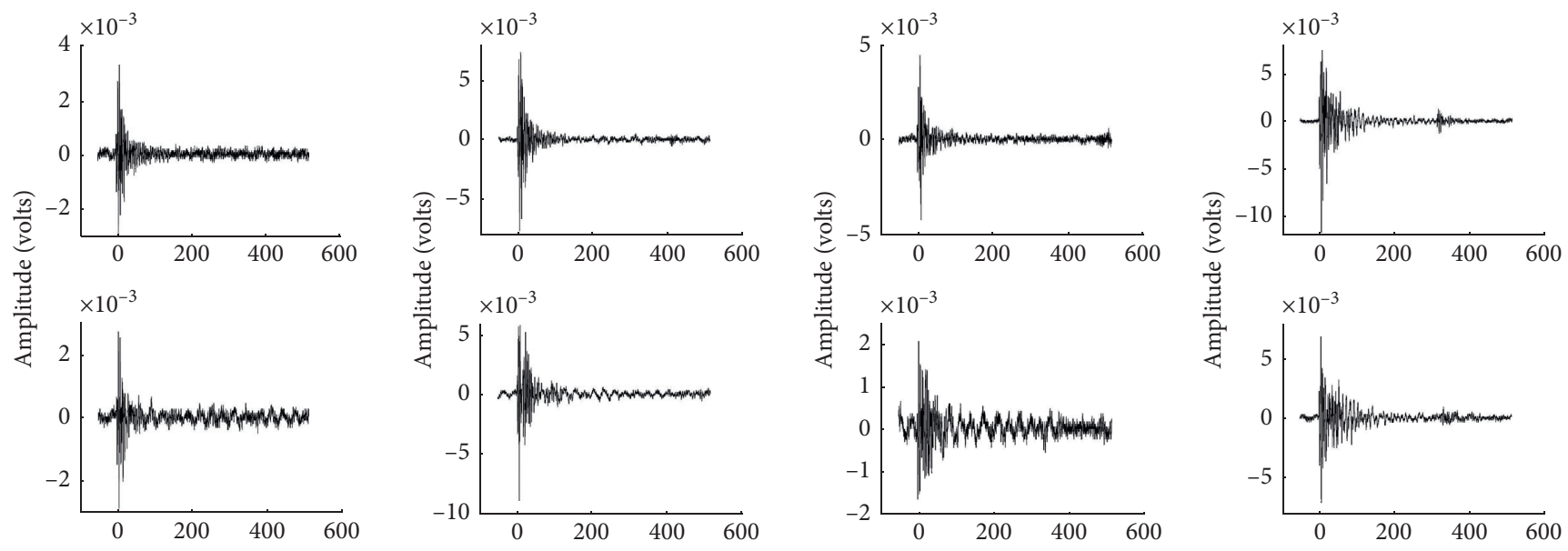

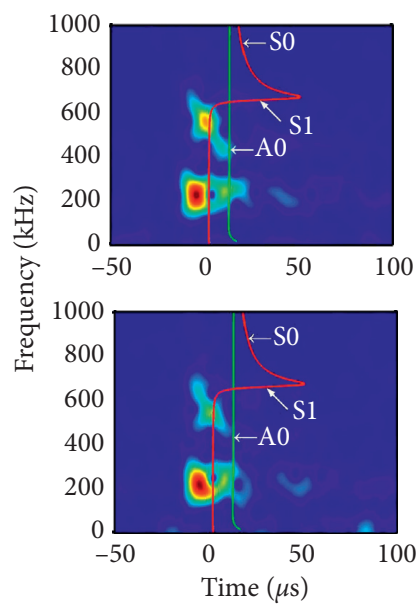

(a)

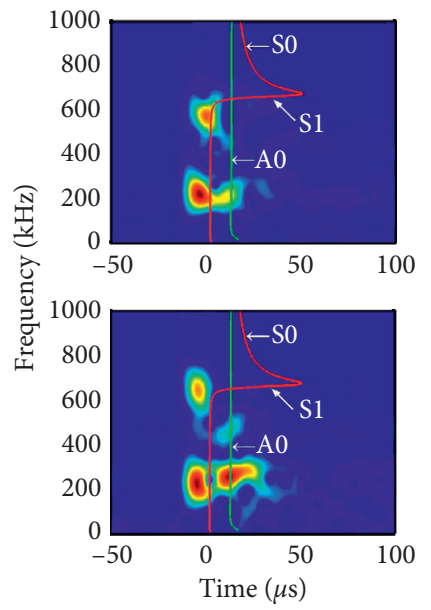

(b)

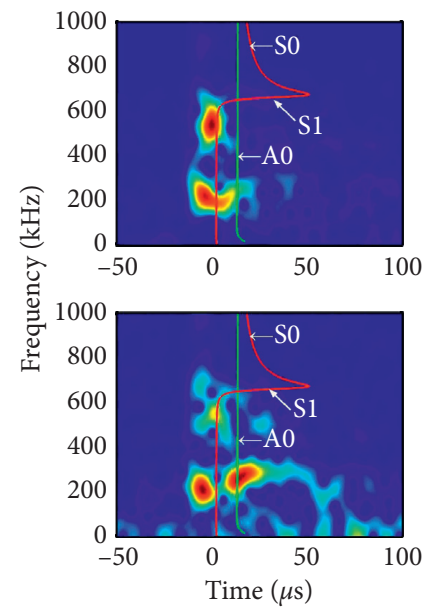

(c)

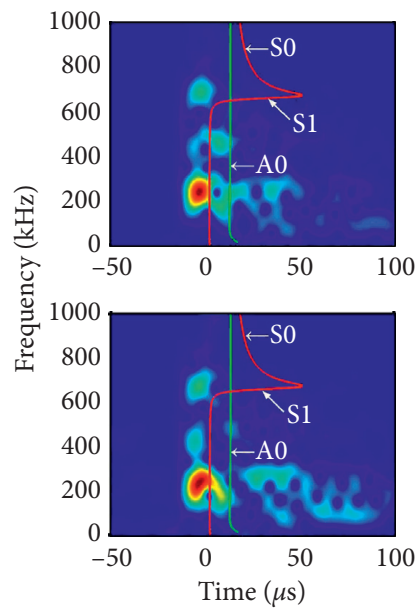

(d)

FIgURE 8: The AE signals and spectrograms in the $\left[0 / 90 / 0 / 90 / 0_{4}\right]_{s}$ layup. (a) $t=39.9 \mathrm{~s}$. (b) $t=75 \mathrm{~s}$. (c) $t=124 \mathrm{~s}$. (d) $t=164 \mathrm{~s}$. 

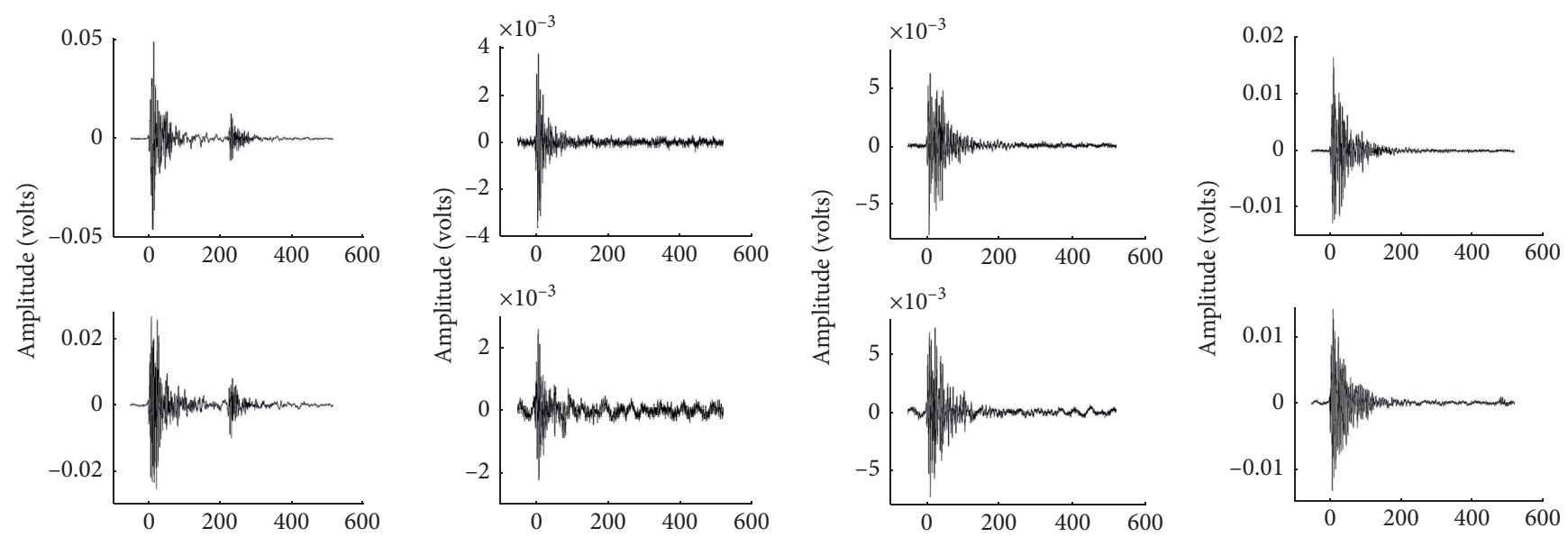

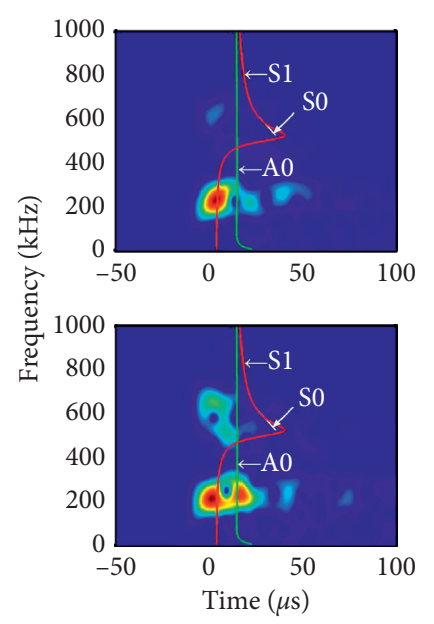

(a)

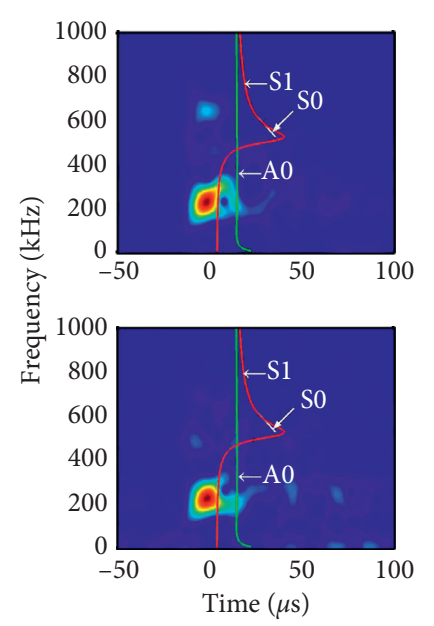

(b)

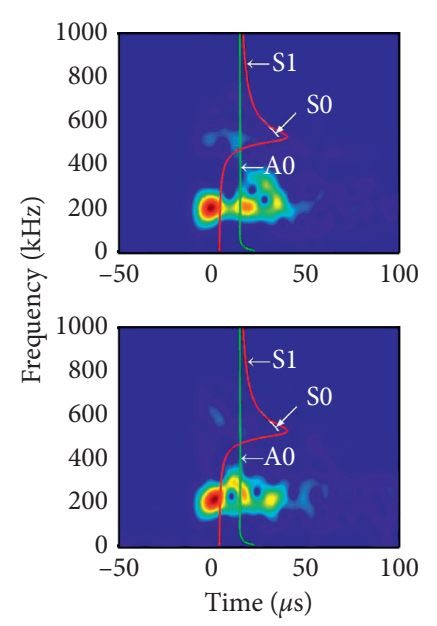

(c)

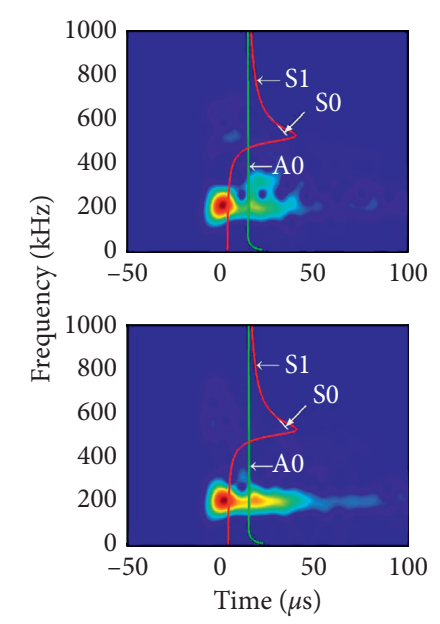

(d)

Figure 9: The AE waveform signal and spectrogram in a $\left[90 / 0 / 90 / 0 / 90_{4}\right]_{s}$ layup. (a) $t=34.8 \mathrm{~s}$. (b) $t=87.2 \mathrm{~s}$. (c) $t=138.3 \mathrm{~s}$. (d) $t=160.4 \mathrm{~s}$.

and $S_{1}$ ) and flexural modes $\left(A_{0}\right.$ and $\left.A_{1}\right)$. For extensional modes $\left(S_{0}\right.$ abd $\left.S_{1}\right)$, the particles inside the plate mainly involve in-plane motion and the deformation of the plate is symmetric about the midthickness plane. For flexural modes $\left(A_{0}\right.$ and $\left.A_{1}\right)$, the particles inside the plate mainly have outof-plane motion and the deformation of the plate is antisymmetric [31, 32]. The manifestation of guided waves in the plate is as shown in Figure 4.

The results are shown in Figures 5(a)-5(d), respectively. The results show that the group velocity of the $S_{0}$ and $S_{1}$ modes coincide when the $45^{\circ}$ layer is not contained, and $A_{1}$ mode does not appear around the frequency field of $1 \mathrm{MHz}$. In addition, the $S_{0}$ mode has a greater velocity and higher frequency than $A_{0}$ mode. This is in accordance with previous research $[33,34]$.

\section{Results and Analysis}

Before the tests, the AE sensors are fixed on the sample to detect whether there is signal received when the machine is not running. If the signal is received, it means that the noise generated by mechanical vibration is detected. In order to reduce the impact of vibration, attach a layer of highdamping rubber near the clamp and test again. If no signal is received, then break a pencil lead on the surface of the sample to check whether the sensors can receive signals normally. During the experiments, the acoustic emission system records the signals, which are processed in MATLAB using short-time Fourier transform (STFT) for further analysis.

3.1. Loading Force and Displacement Analysis. The tensile tests are performed on two layups, namely, $\left[0 / 90 / 0 / 90 / 0_{4}\right]_{s}$ and $\left[90 / 0 / 90 / 0 / 90_{4}\right]_{s}$. The tests are conducted under the same conditions for both layups and the time curves of the loading force and displacement for the two specimens are shown in Figure 6. The maximum loading forces (the force by which the laminate breaks) for $\left[0 / 90 / 0 / 90 / 0_{4}\right]_{s}$ and $[90 / 0 /$ $\left.90 / 0 / 90_{4}\right]_{s}$ are $70.2 \mathrm{KN}$ and $22.8 \mathrm{KN}$, and the break time is $261 \mathrm{~s}$ and $170 \mathrm{~s}$. It can be seen from Figure 6 that, under the same conditions, the laminates with more $0^{\circ}$ plies have better stiffness and strength. In contrast, the laminates with more $90^{\circ}$ layers are more likely to be broken.

The three-point bending tests are performed on the layups of $\left[0_{8}\right]_{s}$ and $\left[0 / 45 / 0 /-45 / 0_{4}\right]_{s}$. Again, the time curves of maximum loading force and displacement are shown in Figure 7 . The break time of the $\left[0_{8}\right]_{s}$ layup is $147 \mathrm{~s}$, and its 

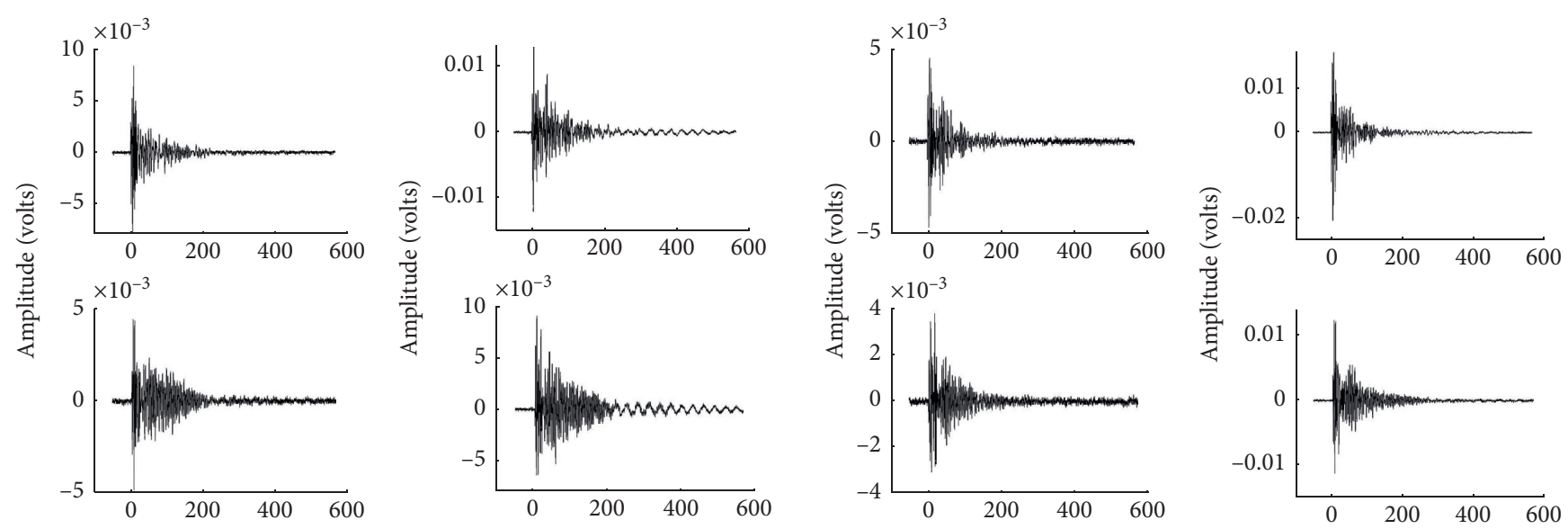

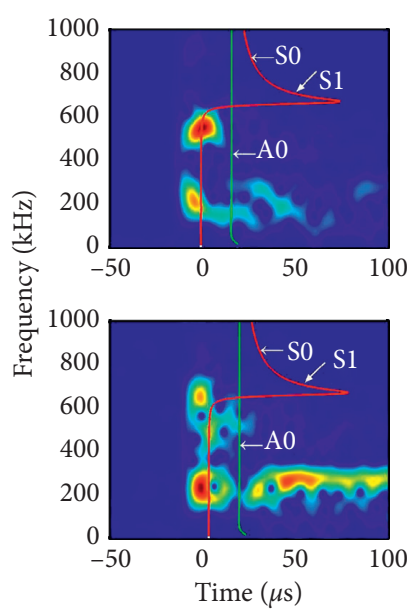

(a)

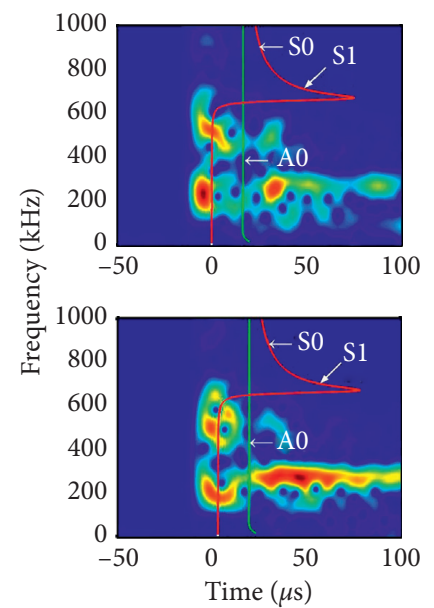

(b)

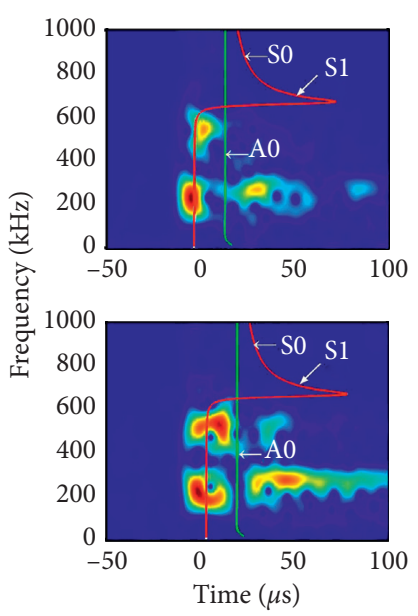

(c)

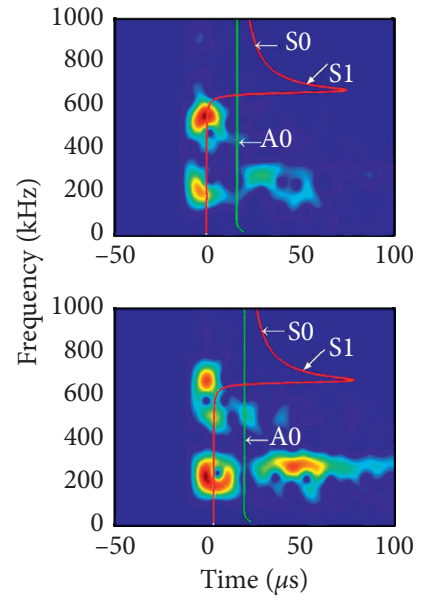

(d)

Figure 10: The AE waveform signal and spectrogram in a $\left[0_{8}\right]_{s}$ layup. (a) $t=28.6 \mathrm{~s}$. (b) $t=56.7 \mathrm{~s}$. (c) $t=109 \mathrm{~s}$. (d) $t=142.4 \mathrm{~s}$.

maximum loading force is $139.6 \mathrm{~N}$. In contrast, the break time of $\left[0 / 45 / 0 /-45 / 0_{4}\right]_{s}$ layup is $185 \mathrm{~s}$ and the maximum loading force is $114 \mathrm{~N}$, as shown in Figures 7(a) and 7(b). As can be seen, the curve of the layups of $\left[0_{8}\right]_{s}$ has a linear trend until reaching the final failure. It shows that the composite laminate has good elastic deformation. While the curve of the laminate with $\pm 45^{\circ}$ plies has the same curve at the beginning of loading, and the region after the load reached a peak value, too significant drop of about $10-30 \%$ of the peak load in the curve was observed, and this sudden drop was due to the weaker shear resistance between the $\pm 45^{\circ}$ plies and other plies causing delamination. After the load drop, the specimen continued to sustain the load but never exceeded the previous peak load until reaching the final failure. It can be found that the laminate with $\pm 45^{\circ}$ plies is more durable when subjected to lateral loading; however, its strength is not as good.

3.2. Analysis of the AE Signals. During the experiment, the $\mathrm{AE}$ system detects and stores significant number of data samples for each signal. For convenience, we consider sets of 6144 consecutive data samples with the sampling interval of $1 \mu$ s for each signal. After the signals are recorded, Short-Time Fast Fourier transform (STFT) is used to obtain the signal spectrogram. Using the distance between sensors $d$ and the group velocity $v_{g}$, the following formula can be obtained:

$$
t=\frac{d}{v_{g}}
$$

where $t$ is the time in $S_{0}$ or $A_{0}$ modes, unit: $\mu$ s; $d$ is the distance between the sensors, unit: $\mathrm{m}$; and $v g$ is the group velocity calculated by DISPERSE software, unit: $\mathrm{m} / \mu \mathrm{s}$.

Then, embed the obtained dispersion curve into the spectrogram to distinguish a useful signal and a noise signal. In the tensile test, the $\mathrm{AE}$ signals collected at different time and the corresponding spectrograms for the layups of [0/90/ $\left.0 / 90 / 0_{4}\right]_{s}$ and $\left[90 / 0 / 90 / 0 / 90_{4}\right]_{s}$ are shown in Figures 8 and 9, respectively. In each figure, the first and third plots are the $\mathrm{AE}$ signals and spectrograms, respectively, which are collected by the 1st sensor. Similarly, In each figure, the second and fourth plots are the AE signals and spectrograms, respectively, which are collected by the 2 nd sensor. In the spectrograms, the white line represents the $S_{0}$ mode, the red line represents the $S_{1}$ mode, and the green line represents the $A_{0}$ mode or $A_{1}$ mode.

When looking at the spectrogram of the $\left[0 / 90 / 0 / 90 / 0_{4}\right]_{s}$ laminate (as shown in Figure 8), most of the frequency components appear to fall into two ranges: one between 

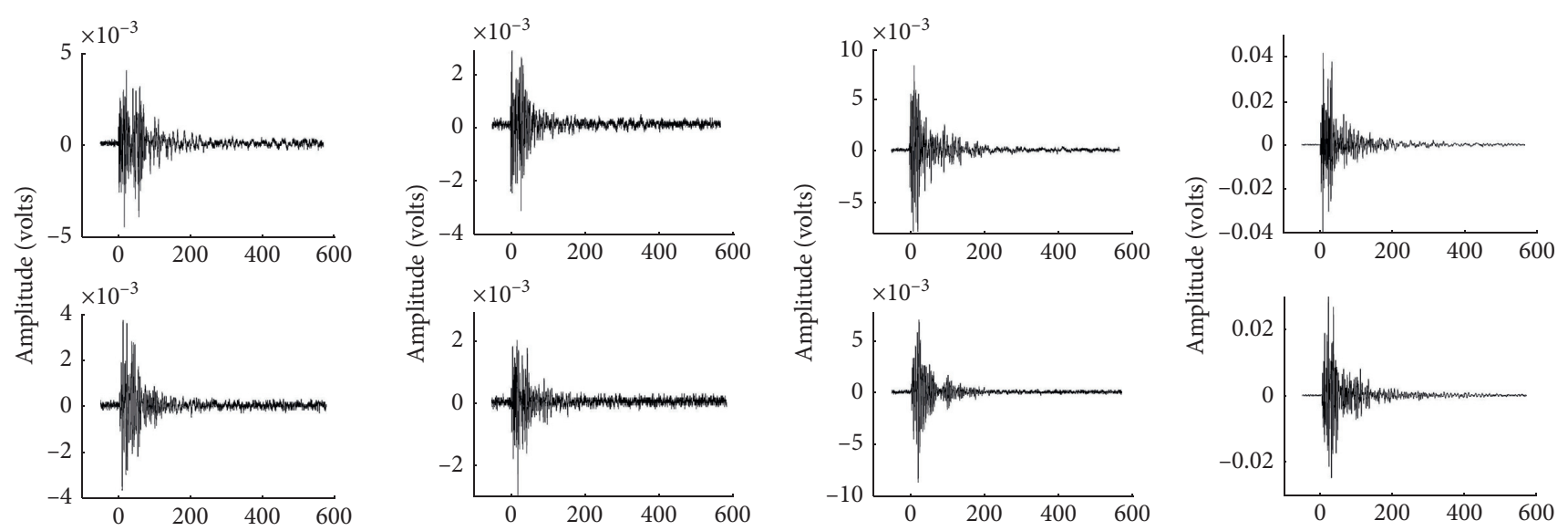

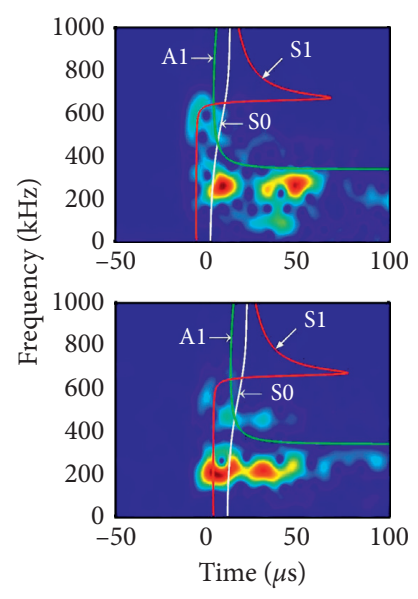

(a)

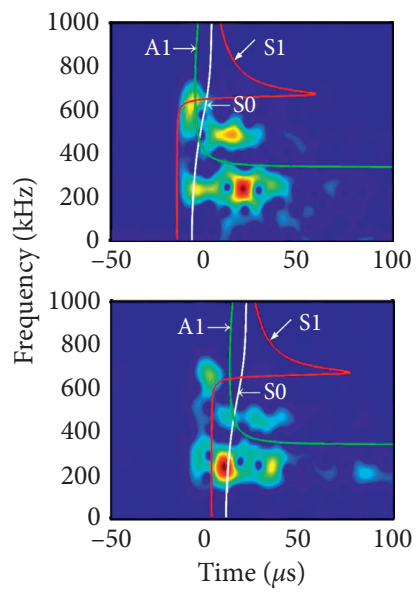

(b)

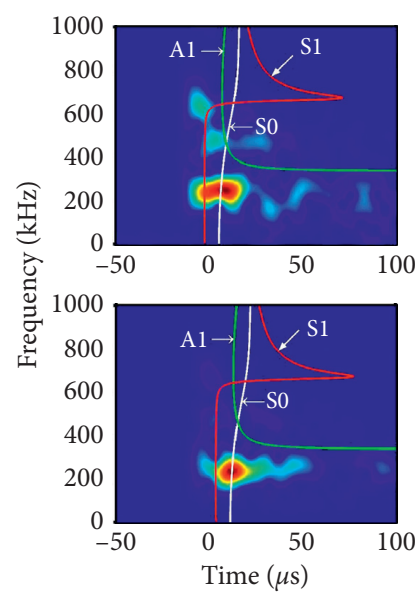

(c)

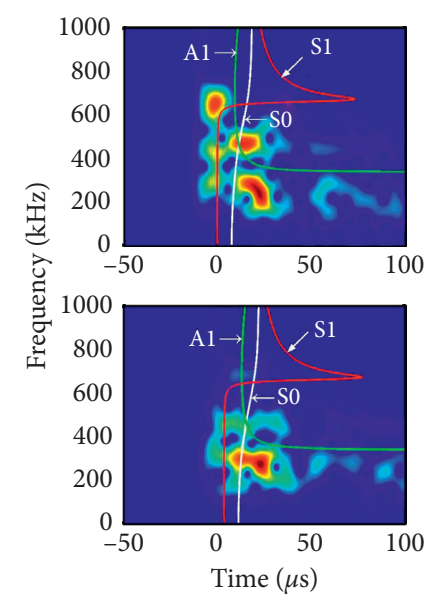

(d)

Figure 11: The AE waveform signal and spectrogram in a $\left[0 / 45 / 0 /-45 / 0_{4}\right]_{s}$ layup. (a) $t=52.2 \mathrm{~s}$. (b) $t=101.9 \mathrm{~s}$. (c) $t=145.3 \mathrm{~s}$. (d) $t=161.8 \mathrm{~s}$.

$100 \mathrm{kHz}$ and $300 \mathrm{kHz}$ and the other between $500 \mathrm{kHz}$ and $700 \mathrm{kHz}$. As stated in Section 1, the two frequency ranges correspond to the failure of matrix crack and fiber fracture. At the early stage of the experiment (as shown in Figure 8(a)), the frequency components corresponding to matrix crack and fiber fracture are very obvious. As time goes by, the frequency range relative to delamination emerges and becomes more obvious (as shown in Figures $8(\mathrm{~b})$ and $8(\mathrm{c})$ ). This is due to the fact that the imposing of pressure gradually causes breaking of the stacking in the laminate. At the later stage, Figure 8(d) shows a significant increase in the frequency range of delamination, whilst that of fiber fracture gradually fades. In addition, the dispersion curves show that when there are multiple peaks in the frequency range (as shown in Figures 8(b) and 8(c)), it can be clearly seen that the $S_{0}$ and $S_{1}$ modes pass through the first frequency peak (near time 0 ), indicating that the extensional mode plays a dominant role at the beginning.

In contrast, when reducing the number of $0^{\circ}$ and increasing the number of $90^{\circ}$ plies, the dominant failure mode of the $\left[90 / 0 / 90 / 0 / 90_{4}\right]_{s}$ laminate is matrix cracks (as shown in Figure 9). Specifically, Figure 9(a) shows that there exists some frequency range of fiber fractures, but with the progress of the experiment, the frequency ranges corresponding to fiber fracture and delamination gradually disappear. Comparing Figures 8 and 9, it can be seen that changing the number and relative position of $0^{\circ}$ and $90^{\circ}$ plies leads to significant difference in the change of failure modes. This clearly shows that better stacked sequences can lead to lower risk of fiber fractures and delamination, even when a hole is introduced into the laminates.

On the other hand, three-point bending tests were carried out on the specimens of $\left[0_{8}\right]_{s}$ and $\left[0 / 45 / 0 /-45 / 0_{4}\right]_{s}$. The time series and spectrograms of both experiments are shown in Figures 10 and 11.

This time, the spectrograms of the acoustic signals from the bending test are more complex than those from the tensile test. A total of three frequency ranges can be observed in Figure 10, with the ranges of $100-300 \mathrm{kHz}, 400-600 \mathrm{kHz}$, and $500-700 \mathrm{kHz}$. Because the loading direction is perpendicular to the specimen and it contains only $0^{\circ}$ fiber direction, delamination and fiber fracture occur simultaneously throughout the experiment. Including the dispersion curves into the spectrograms, we can see that the $S_{0}$ and $S_{1}$ modes have more prominent effect on the failure modes, while the $A_{0}$ mode has basically no effect.

Meanwhile, when $\pm 45^{\circ}$ plies are included into the laminate, it can be seen from Figure 11 that there are also three different frequency ranges, but the frequency ranges 


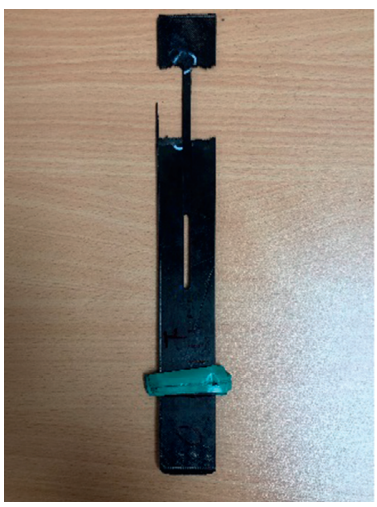

(a)

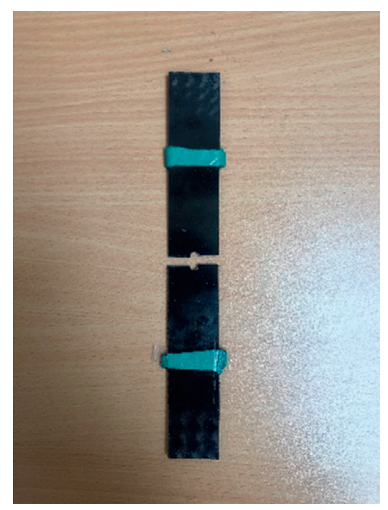

(b)

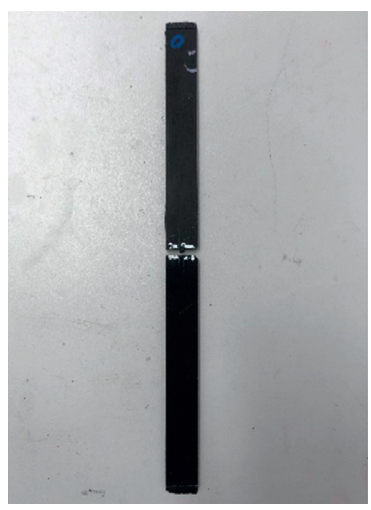

(c)

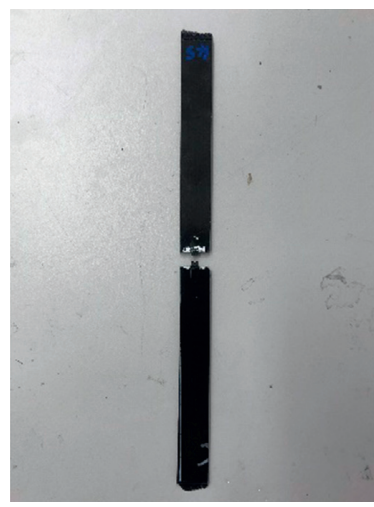

(d)

Figure 12: Broken specimens. (a) $\left[0 / 90 / 0 / 90 / 0_{4}\right]_{s}$. (b) $\left[90 / 0 / 90 / 0 / 90_{4}\right]_{s}$. (c) $\left[0_{8}\right]_{s}$. (d) $\left[0 / 45 / 0 /-45 / 0_{4}\right]_{s}$.

corresponding to delamination and fiber fracture change with the progress of experiment. Recall the loading force curve of this laminate (as shown in Figure 7(b)), the time of $t=101.9$ s (Figure 11(b)) is close to the time when the maximum loading force is imposed. At this time, the frequency range of delamination is the most obvious. When the force is continuously applied, the delamination reduces the number of layers perpendicular to the direction of the loading force and caused the loading force to reduce, so that the frequency ranges corresponding to delamination and fiber fracture are not noticeable (as shown in Figure 11(c)). At the end of the experiment, Figure 11(d) shows that frequency range of delamination appears again until the sample breaks. In addition, the dispersion curves of this specimen are also different. This time, there is no $A_{0}$ mode in the laminate with $\pm 45^{\circ}$ plies, but the $A_{1}$ mode appears, indicating there is no relation between this mode and matrix crack. Comparing Figures 10 and 11, one can see that, for cracked laminates with different layups, all the three failures can be observed. However, there is clear difference between the two laminates; it can be seen that laminate with $\pm 45^{\circ}$ plies are more apt to suffer from delamination.

The results of tensile test and bending test indicate that the different layups of laminates have significant influence on the failure mode. Designing an appropriate layup may reduce the risk of failure.

Finally, the images of broken laminates of [0/90/0/90/ $\left.0_{4}\right]_{s}$ and $\left[90 / 0 / 90 / 0 / 90_{4}\right]_{s}$ are shown in Figure 12. As shown in Figure 12(a), since the breaking force of the fibers is greater than the bonding force between the fibers during the tensile test, a part of the specimen was drawn out when it broke. In contrast, the breaking section was very flat for the laminate of $\left[90 / 0 / 90 / 0 / 90_{4}\right]_{s}$, as shown in Figure 12(b). In the bending test, obvious matrix fracture can be observed for the specimen of $\left[0_{8}\right]_{s}$, as shown in Figure 12(c). In contrast, obvious delamination can be observed for the specimen of $\left[0 / 45 / 0 /-45 / 0_{4}\right]_{s}$, as shown in Figure 12(d).

\section{Conclusions}

This paper performs failure mode analysis in the defective composite laminates using the $\mathrm{AE}$ technique. A new analysis method is introduced by combining the dispersion curve of the plate wave and the spectrogram of the AE signal. Based on the tests on around 20 laminates, the following conclusions can be drawn. (i) In the two experiments, all laminates have good elastic deformation at the beginning of loading. The more fiber tow parallel to the loading direction, the stronger the tensile strength in the tensile test. However, the $\pm 45^{\circ}$ ply is likely to cause delamination, which is more durable when subjected to vertical loading, but the strength is not good in the bending test. (ii) During the loading process, the evolution of the failure mode is relatively stable and will not change by time, but the ply structure will change the generation of a certain failure mode. In addition, multiple failure modes occur simultaneously in the same laminates. The combination of the spectrogram and the dispersion curves of guided waves shows that the matrix crack is more susceptible to guided wave than other failure modes. In order to provide a practical guide to the design of composite laminates, for further study, more tests should be conducted on laminates with different combinations of plies (both defective and without defect) to give a more thorough analysis on the impact of ply combination on the strength and reliability.

\section{Data Availability}

The data in the manuscript are obtained through experiments. If necessary, original data can be provided to ensure the repeatability of the experiment.

\section{Conflicts of Interest}

The authors declare that they have no conflicts of interest regarding the publication of this paper.

\section{References}

[1] S. Rana and R. Fangueiro, Advanced Composite Materials for Aerospace Engineering: Processing, Properties and Applications, Woodhead Publishing, Sawston, UK, 2016.

[2] E. C. Botelho, R. A. Silva, L. C. Pardini, and M. C. Rezende, "A review on the development and properties of continuous 
fiber/epoxy/aluminum hybrid composites for aircraft structures," Materials Research, vol. 9, no. 3, pp. 247-256, 2006.

[3] K. Morioka, Y. Tomita, and K. Takigawa, "High-temperature fracture properties of CFRP composite for aerospace applications," Materials Science and Engineering: A, vol. 319-321, pp. 675-678, 2001.

[4] P. A. Smith and K. J. Pascoe, "The effect of stacking sequence on the bearing strengths of quasi-isotropic composite laminates," Composite Structures, vol. 6, no. 1-3, pp. 1-20, 1986.

[5] P. F. Liu and J. Y. Zheng, "Progressive failure analysis of carbon fiber/epoxy composite laminates using continuum damage mechanics Materials," Science and Engineering: A, vol. 485, no. 1-2, pp. 711-717, 2008.

[6] A. Kondo, Y. Sato, H. Suemasu, and Y. Aoki, "Fracture resistance of carbon/epoxy composite laminates under mixedmode II and III failure and its dependence on fracture morphology," Advanced Composite Materials, vol. 20, no. 5, pp. 405-418, 2011.

[7] P. F. Liu, B. B. Liao, L. Y. Jia, and X. Q. Peng, "Finite element analysis of dynamic progressive failure of carbon fiber composite laminates under low velocity impact," Composite Structures, vol. 149, pp. 408-422, 2016.

[8] B. Muravin, "Acoustic emission science and technology," Journal of Building and Infrastructure Engineering of the Israeli Association of Engineers and Architects, vol. 1, pp. 4-5, 2009.

[9] L. Sun and Y. Li, "Acoustic emission sound source localization for crack in the pipeline," in Proceedings of the 2010 Chinese Control and Decision Conference, pp. 4298-4301, IEEE, Xuzhou, China, May 2010.

[10] R. V. Sagar and B. K. R. Prasad, "A review of recent developments in parametric based acoustic emission techniques applied to concrete structures," Nondestructive Testing and Evaluation, vol. 27, no. 1, pp. 47-68, 2012.

[11] A. Nair and C. S. Cai, "Acoustic emission monitoring of bridges: review and case studies," Engineering Structures, vol. 32, no. 6, pp. 1704-1714, 2010.

[12] C. Baker, G. N. Morscher, V. V. Pujar, and J. R. Lemanski, "Transverse cracking in carbon fiber reinforced polymer composites: modal acoustic emission and peak frequency analysis," Composites Science and Technology, vol. 116, pp. 26-32, 2015.

[13] J. Yousefi, R. Mohamadi, M. Saeedifar, M. Ahmadi, and H. Hosseini-Toudeshky, "Delamination characterization in composite laminates using acoustic emission features, micro visualization and finite element modeling," Journal of Composite Materials, vol. 50, no. 22, pp. 3133-3145, 2016.

[14] S. Woo and N. Choi, "Analysis of fracture process in singleedge-notched laminated composites based on the high amplitude acoustic emission events," Composites Science and Technology, vol. 67, no. 7-8, pp. 1451-1458, 2007.

[15] L. Michalcov'a, P. Belsky', and L. Petrusov'a, "Composite panel structural health monitoring and failure analysis under compression using acoustic emission," Journal of Civil Structural Health Monitoring, vol. 8, no. 4, pp. 607-615, 2018.

[16] M. G. Sause, "Acoustic emission source identification in large scale fibre reinforced composites," Journal of Acoustic Emission, vol. 33, p. S223, 2016.

[17] I. M. De Rosa, C. Santulli, and F. Sarasini, "Acoustic emission for monitoring the mechanical behaviour of natural fibre composites: a literature review," Composites Part A: Applied Science and Manufacturing, vol. 40, no. 9, pp. 1456-1469, 2009.
[18] R. Gutkin, C. J. Green, S. Vangrattanachai, S. T. Pinho, P. Robinson, and P. T. Curtis, "On acoustic emission for failure investigation in CFRP: pattern recognition and peak frequency analyses," Mechanical Systems and Signal Processing, vol. 25, no. 4, pp. 1393-1407, 2011.

[19] A. Mahdian, J. Yousefi, M. Nazmdar, N. Zarif Karimi, M. Ahmadi, and G. Minak, "Damage evaluation of laminated composites under low-velocity impact tests using acoustic emission method," Journal of Composite Materials, vol. 51, no. 4, pp. 479-490, 2017.

[20] A. C. Okafor, N. Singh, N. Singh, and B. N. Oguejiofor, "Acoustic emission detection and prediction of fatigue crack propagation in composite patch repairs using neural network," Journal of Thermoplastic Composite Materials, vol. 30, no. 1, pp. 3-29, 2017.

[21] M. Saeedifar, M. A. Najafabadi, D. Zarouchas, H. H. Toudeshky, and M. Jalalvand, "Clustering of interlaminar and intralaminar damages in laminated composites under indentation loading using Acoustic Emission," Composites Part B: Engineering, vol. 144, pp. 206-219, 2018.

[22] P. F. Liu, J. K. Chu, Y. L. Liu, and J. Y. Zheng, "A study on the failure mechanisms of carbon fiber/epoxy composite laminates using acoustic emission," Materials \& Design, vol. 37, pp. 228-235, 2012.

[23] C. Huang, S. Ju, M. He et al., "Identification of failure modes of composite thin-ply laminates containing circular hole under tension by acoustic emission signals," Composite Structures, vol. 206, pp. 70-79, 2018.

[24] D. Baccar and D. Söffker, "Identification and classification of failure modes in laminated composites by using a multivariate statistical analysis of wavelet coefficients," Mechanical Systems and Signal Processing, vol. 96, pp. 77-87, 2017.

[25] M. R. Venturini Autieri and J. M. Dulieu-Barton, "Initial studies for AE characterisation of damage in composite materials," Advanced Materials Research, vol. 13-14, pp. 273-280, 2006.

[26] H. Jeong and Y.-S. Jang, "Wavelet analysis of plate wave propagation in composite laminates," Composite Structures, vol. 49, no. 4, pp. 443-450, 2000.

[27] S. H. D'raz Vald'es and C. Soutis, "Real-time nondestructive evaluation of fiber composite laminates using low-frequency Lamb waves," The Journal of the Acoustical Society of America, vol. 111, no. 5, pp. 2026-2033, 2002.

[28] Y. Okabe, K. Fujibayashi, M. Shimazaki, H. Soejima, and T. Ogisu, "Delamination detection in composite laminates using dispersion change based on mode conversion of lamb waves," Smart Materials and Structures, vol. 19, no. 11, p. 115013, 2010.

[29] A. Azzam and W. Li, "An experimental investigation on the three-point bending behavior of composite laminate," IOP Conference Series: Materials Science and Engineering, vol. 62, no. 1, Article ID 012016, 2014.

[30] ASTM 2007, D7246M-2007, Standard Test Method of Flexural Properties of Polymer Matrix Composite Materials, ASTM 2007, D7246M-2007, West Conshohocken, PA, USA, 2007.

[31] M. R. Gorman, "Plate wave acoustic emission," The Journal of the Acoustical Society of America, vol. 90, no. 1, pp. 358-364, 1991.

[32] B. Feng, A. L. Ribeiro, and H. G. Ramos, "Interaction of lamb waves with the edges of a delamination in CFRP composites and a reference-free localization method for delamination," Measurement, vol. 122, pp. 424-431, 2018. 
[33] M. Surgeon and M. Wevers, "Modal analysis of acoustic emission signals from CFRP laminates," Ndt \& e International, vol. 32, no. 5, pp. 311-322, 1999.

[34] M. R. Gorman and W. Prosser, "AE source orientation by plate wave analysis," Structural Health Monitoring, vol. 9, no. 4, pp. 283-288, 1991. 